\title{
One-shot Preparation of Polyacrylamide/Poly(sodium Styrenesulfonate) Double Network Hydrogels for Rapid Optical Tissue Clearing
}

\author{
Takayuki Koda, ${ }^{1}$ Shunsuke Dohi, ${ }^{1}$ Hedeki Tachi, ${ }^{2}$ Yasuhito Suzuki, ${ }^{1}$ Chie Kojima,${ }^{*}$ and Akikazu \\ Matsumoto $^{1^{*}}$ \\ ${ }^{1}$ Department of Applied Chemistry, Graduate School of Engineering, Osaka Prefecture University, \\ 1-1 Gakuen-cho, Naka-ku, Sakai, Osaka 599-8531, Japan \\ ${ }^{2}$ Research Division of Polymer Functional Materials, Izumi Center, Osaka Research Institute of Industrial Science \\ and Technology, 2-7-1 Ayumino, Izumi, Osaka 594-1157, Japan \\ *Corresponding authors. E-mail: matsumoto@chem.osakafu-u.ac.jp and kojima@chem.osakafu-u.ac.jp
}

\section{Contents}

Figure S1. ${ }^{1} \mathrm{H}$ NMR spectra of a mixture of AAm and SS in the presence of VA-044 (a) before and (b) after polymerization in PBS- $\mathrm{D}_{2} \mathrm{O}$ at $37{ }^{\circ} \mathrm{C}$ for $3 \mathrm{~h}$. $[\mathrm{AAm}]_{0} /[\mathrm{SS}]_{0}=1 / 1$ molar ratio in the feed. An asterisk indicates 1,2-dimethoxyethane as the internal standard and $\mathrm{H}_{2} \mathrm{O}$.

Figure S2. Comonomer-copolymer composition curve for the copolymerization of AAm $\left(M_{1}\right)$ and SS $\left(\mathrm{M}_{2}\right)$ calculated based on the monomer consumption ratio after the polymerization for $1 \mathrm{~h}$. The curves were depicted using $r_{1}=0.10$ and $r_{2}=6.6$.

Figure S3. Fineman-Ross plots for the determination of monomer reactivity ratios for the copolymerization system of AAm and SS.

Figure S4. ${ }^{1} \mathrm{H}$ NMR spectra of the AAm/SS gels swelled in $\mathrm{D}_{2} \mathrm{O}$. The gels were prepared under the conditions of various $[\mathrm{AAm}]_{0} /[\mathrm{SS}]_{0}$ ratios.

Figure S5. Change in the swelling ratios of AAm/SS gels, AAm gel, and SS gel during immersion in distilled water at room temperature.

Figure S6. Strain dependence of storage modulus (open circles) and loss modulus (closed circles) for (a)-(e) AAm/SS gels and (f) AAm gel. The [AAm] $/[\text { [SS }]_{0}$ ratio was (a) 6/1, (b) $3 / 1,(c) 1 / 1$, (d) $1 / 3$, and (e) $1 / 6$ in the feed for the preparation of the gels. 

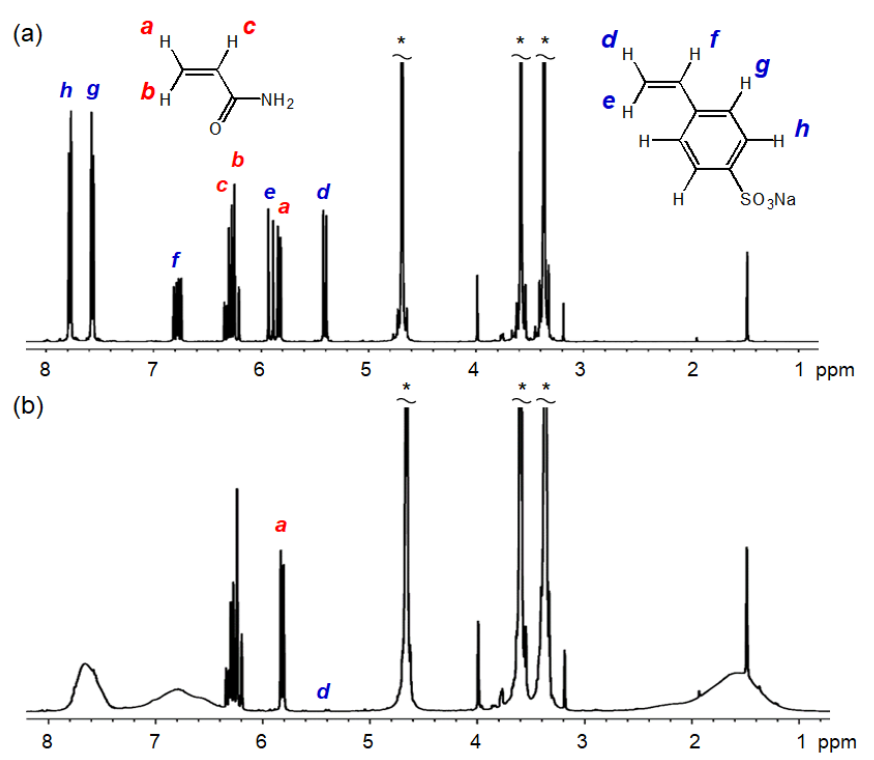

Figure S1. ${ }^{1} \mathrm{H}$ NMR spectra of a mixture of AAm and SS in the presence of VA-044 (a) before and (b) after polymerization in $\mathrm{PBS}-\mathrm{D}_{2} \mathrm{O}$ at $37{ }^{\circ} \mathrm{C}$ for $3 \mathrm{~h}$. $[\mathrm{AAm}]_{0} /[\mathrm{SS}]_{0}=1 / 1$ molar ratio in the feed. An asterisk indicates 1,2-dimethoxyethane as the internal standard and $\mathrm{H}_{2} \mathrm{O}$.

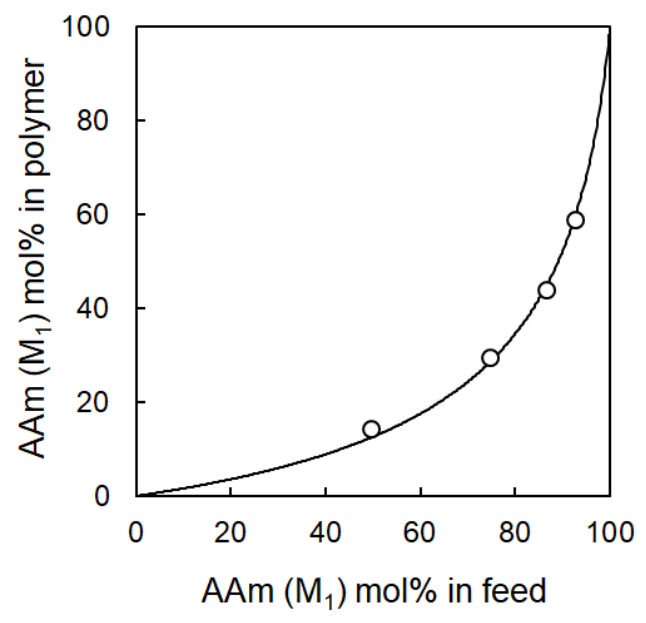

Figure S2. Comonomer-copolymer composition curve for the copolymerization of AAm $\left(M_{1}\right)$ and SS $\left(\mathrm{M}_{2}\right)$ calculated based on the monomer consumption ratio after the polymerization for $1 \mathrm{~h}$. The curves were depicted using $r_{1}=0.10$ and $r_{2}=6.6$. 

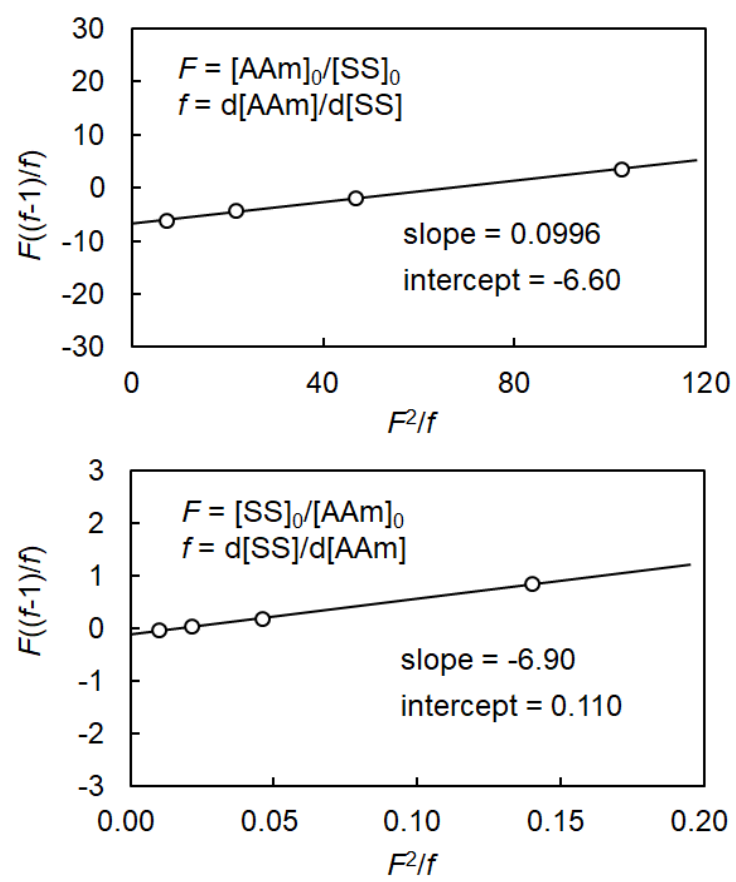

Figure S3. Fineman-Ross plots for the determination of monomer reactivity ratios for the copolymerization system of AAm and SS.
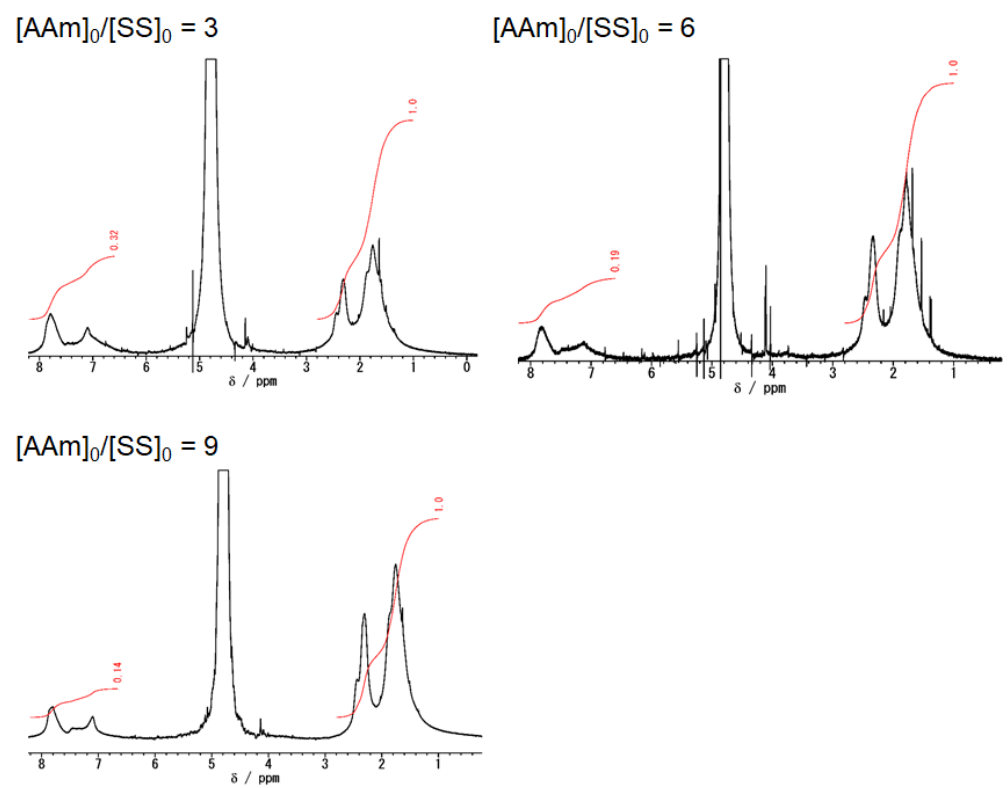

Figure S4. ${ }^{1} \mathrm{H}$ NMR spectra of the AAm/SS gels swelled in $\mathrm{D}_{2} \mathrm{O}$. The gels were prepared under the conditions of various $[\mathrm{AAm}]_{0} /[\mathrm{SS}]_{0}$ ratios. 


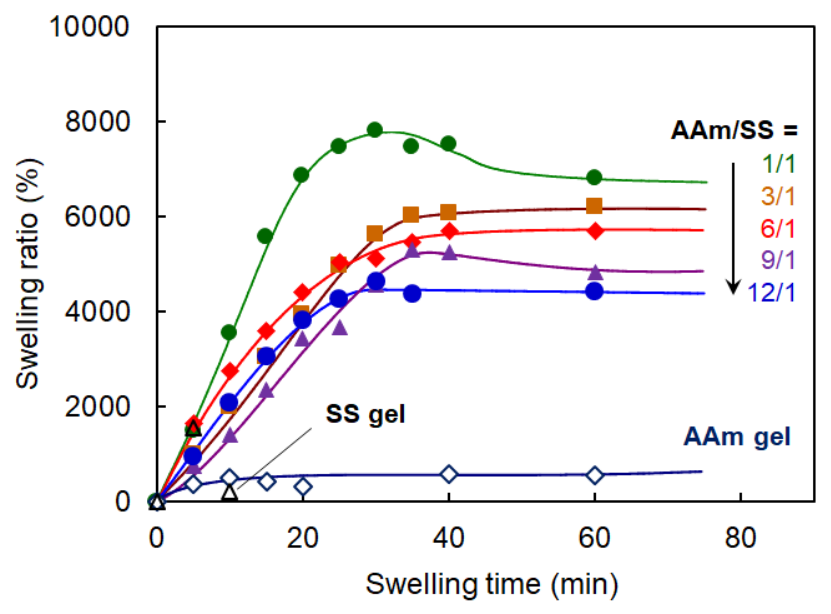

Figure S5. Change in the swelling ratios of AAm/SS gels, AAm gel, and SS gel during immersion in distilled water at room temperature.

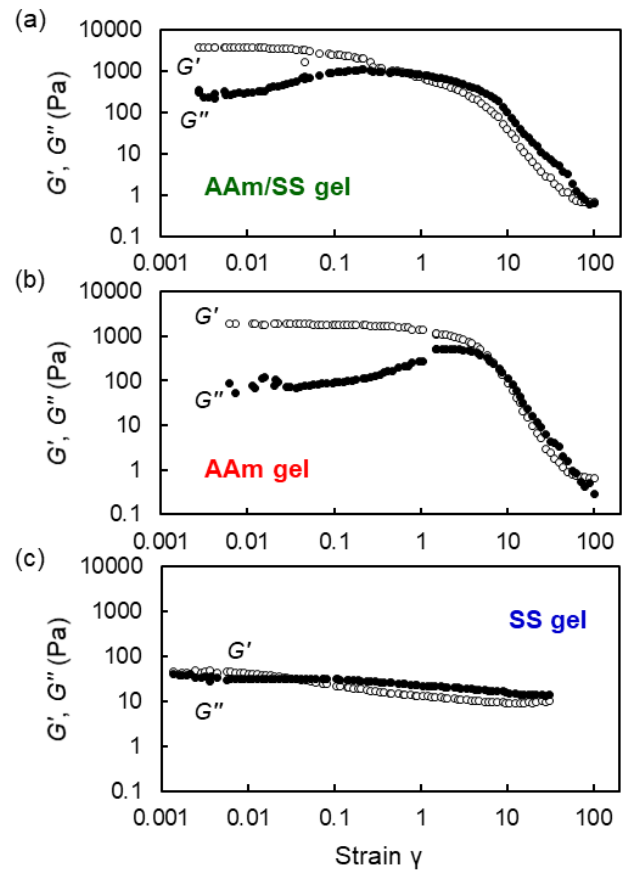

Figure S6. Strain dependence of storage modulus (open circles) and loss modulus (closed circles) for (a) AAm/SS gel (1/1), (b) AAm gel, and (c) SS gel. 